\title{
Sciendo
}

ECONOMICS AND CULTURE 18(2), 2021

DOI: $10.2478 /$ jec-2021-0011

\section{THE DIFFERENCE BETWEEN LEGAL CONTROL AND MATERIAL CONTROL - COORDINATION OF ACCESS RIGHTS IN SHARED WORKSPACES}

\author{
Uwe Busbach \\ University of Applied Sciences Kehl, School of Public Administration, Kehl, Germany, busbach@hs- \\ kehl.de
}

Received 03 September 2021; accepted 23 November 2021

\begin{abstract}
Research purpose. Modern work is increasingly taking place in temporary workgroups embedded in decentralized work environments that transcend organizational boundaries. The first implementations of the shared workspace idea emerged in the 1990s in the CSCW research area and are now firmly integrated into the working world with systems such as Google Drive, OneDrive or Dropbox. However, when it comes to accessing documents, problems arise in terms of coordinating access to documents. Who can access the documents, modify them, and upload them back to the shared workspace? It should be noted that concurrent changes can lead to inconsistencies. Furthermore, incorrect changes to the content of documents can have economic and legal consequences. Who is responsible for this? Strict access control can avoid this problem if necessary. However, it contradicts the approach of agile cooperation, which benefits, among other things, from access to documents that is not restricted in terms of time and place.
\end{abstract}

Design / Methodology / Approach. The article proposes a semantic approach for access coordination of shared workspaces. Its basis is the legal distinction between the levels of legal control (owner) and material control (possessor). The owner of an object has the right and the duty to allow the other participants of the shared workspace to access it, i.e., to have material control. This is done through an agreement between the owner and the possessor, which specifies the conditions of material control. In addition to coordinating access, the owner is also responsible for arbitrating in case of conflict and deciding which changes are valid and which are not.

Findings. Transferring the distinction between owner and possessor leads to three possible classes of conflicts: Ownership vs ownership, ownership vs possession, and possession vs possession. Conflict schemes within these classes of conflict are analyzed in detail. On the one hand, it is possible to use strict, conflict-avoiding settings, but this tends to limit cooperation. On the other hand, greater cooperation agility can be enabled if the owner situationally controls access or if the owner has preset flexible response tactics in case a conflict arises. A closer look at possible conflict classes shows that it is necessary to adapt the legal concepts of owner and possessor to the cooperation situation.

Originality / Value / Practical implications. The concept of the legal distinction between owner and possessor has not yet been applied to the domain of access coordination in shared workspaces. This approach can introduce the previously missing semantics for access coordination, at least on an informal basis. It also improves participants' awareness of the context of cooperation.

Keywords: Shared Workspaces; access coordination; conflict resolution

JEL codes: M15.

Citation: Busbach, R. (2021). The difference between legal control and material control - coordination of access rights in shared workspaces. Economics and Culture, 18(2), 15-27. https://doi.org/10.2478/jec-2021-0011 


\section{Introduction}

Decentralization of organizations and companies has become a significant success factor in today's business world. Outsourcing, offshoring, joint ventures, and international consortia have led to work environments that are geographically distributed across organizational and national boundaries. This trend toward decentralization of work processes has been manifested by the increasing availability of the Internet over the past 20 years.

In this environment, the results from the research area of computer-supported cooperative work (CSCW) from the 1990s have largely been incorporated into everyday working life: Synchronous computer-based support systems such as videoconferencing systems, virtual whiteboards, etc. are now common tools - reinforced by the digitization push of the COVID-19 pandemic. Computerbased support systems such as instant messaging, shared workspaces, etc., cover asynchronous support needs.

The idea of supporting temporally and spatially separated cooperation with the metaphor of the shared workspace emerged in the early 1990s from, among other things, research that revealed the weaknesses of workflow systems in supporting informal processes (Kreifelts et al. 1991). The approach of enabling workgroups in decentralized and cross-organizational work environments to access (shared) information objects anytime and anywhere on the basis of a minimal technical infrastructure through shared workspaces is standard today. Since the first results and implementations of CSCW research in this area (e.g., Kreifelts et al., 1993; Agostini et al., 1996; Bäcker \& Busbach, 1996; Bentley et al., 1997), shared workspaces have been integrated into everyday life - albeit sometimes with reduced functionality in terms of awareness concepts (e.g., cloud-based solutions such as Google-Drive (Google, 2021) or OneDrive (Microsoft, 2021a). Essential functions of shared workspaces are the provision of information about the work itself and the exchange of data that is processed jointly. Access to data in a shared workspace is not limited by time or location. Actions are logged in so-called events, and the concepts of container (folder) and content are used to structure shared workspaces.

Access to a workspace, i.e., the container/folder, and particularly to information objects stored in the workspace, i.e., the content, must be coordinated to avoid possible inconsistencies due to concurrent, competing changes. The following scenario describes a (simple) distributed work environment. It clearly shows that unforeseen situations can arise within cooperation that require flexible reaction patterns. Using the scenario described below, we discuss aspects of collaborative work and concurrency control solutions developed in this article.

Three people - e.g. Anna, Bert, Clara - work together to create a proposal for a tender. Although Clara is responsible for the project and the documents to be created, the work packages have been divided so that each of the three participants is assigned specific documents to work on. A meeting will be held on Thursday to discuss the results and adjust as necessary. Anna realizes that she still needs to change minor text passages so that the bid can be submitted on time the next day and decides to make these changes the next morning during a business trip. To edit the documents, Anna wants to use a laptop to write back the changes online. Bert is given the task by Clara to merge the various documents and submit them by the deadline on Friday afternoon. During the business trip, a defect occurs in Anna's portable device (hard drive failure, network card failure, etc.). Anna is no longer able to make the necessary changes to the bid. What happens now? Bert takes over Anna's work. He can do this either after explicit agreement with Anna - e.g. in a telephone conversation - or simply because he cannot reach Anna and suspects technical problems. In addition to the changes discussed the previous day, Bert makes further changes because he has received information from informal sources about offers from possible competitors. However, Bert is currently unable to reach the responsible Clara to inform her of his more extensive changes to the bid. He nevertheless decides to submit the new version of the bid by the deadline on Friday. If necessary, Anna and Clara check during the next week whether and to what extent the changes they consider necessary have been made. There may be discrepancies from the participants' respective points of view. What is the "correct" version?

The scenario shows the dynamics and situational dependence of cooperation. Several people access a shared workspace that contains the information objects to be processed within the cooperation. The question arises whether and in what way access to the information objects can 
and must be coordinated and controlled. Of course, the scenario describes an exceptional situation, but it is precisely such circumstances that show the problems that arise within cooperation.

The goal of concurrency control for a shared workspace must be to implement as free as possible, non-restrictive information access coordination within concurrent cooperative activities. Instead of restricting the concurrency of activities, the persons involved should be mutually informed about their actions and involved in maintaining data integrity. A situation where actions cannot be executed because data integrity is compromised from the perspective of the application's concurrency control, even though there is no conflict from the perspective of the cooperating participants, should be avoided. Instead of the classical concurrency control, cooperative access coordination has to be implemented, which allows to include information about the current working context.

In this article, an interdisciplinary approach is presented that examines the distinction between the levels of legal control (owner) and material control (possessor), following the legal system as a basis for access control. In transferring this concept from legal sciences, several questions arise, the answers to which are the focus of the article.

How can the concept of an owner be applied to shared workspaces? What are the rights and obligations of an owner? How can owners of an information object allow or deny other participants access to material possession? How can owners of information objects that interfere with each other resolve the interference?

How can the concept of a possessor be applied to shared workspaces? What are the rights and obligations of a possessor? Which types of possession are mutually exclusive, and which can coexist? What guarantees does the possessor have with regard to his material possession vis-à-vis the owner of the object and, if applicable, owners of other objects that correlate with his object?

In summary, the above questions relate to potential conflicts within cooperation. Understanding their nature can serve as a basis for the future development of procedures to coordinating access to shared workspaces, considering semantics on an informal basis.

\section{Literature review: Access Coordination in Shared Workspaces}

The use of cooperation support systems in general and of shared workspaces, in particular, requires distributed systems at the technical level so that cooperation partners can access documents asynchronously at any time and from any location. The main characteristic of a distributed system is that its software is installed on networked computers that exchange messages asynchronously. To the user, the system appears as a single system even though it is distributed (Tanenbaum \& van Steen 2002). Since it cannot always be assumed that the computers in the network will operate without errors or that the network itself will function, replications of data or files are often used to increase availability. The data objects are stored at different locations in the network. Consequently, simultaneous changes to individual replicas by different users can lead to consistency problems similar to those described in the cooperation scenario in the introduction. At the same time, distributed systems are an enabling technology for cooperation support systems. Therefore, it is interesting to investigate to what extent distributed systems solve the problem of consistency in the presence of concurrent changes and whether this approach can be applied to the cooperation scenario.

It can be concluded that the trade-off between availability and consistency that exists in distributed systems occurs accordingly in cooperation situations. The notion of availability is more complex in distributed systems. However, the perspective of the necessary access to data more precisely, in the context of cooperation, to information objects like documents needed for the joint processing of a task - is identical. Increasing availability can be achieved by temporarily allowing different replicas of a document using so-called optimistic techniques (Saito \& Shapiro, 2005). However, this can lead to temporary inconsistencies that have to be resolved. If one wants to avoid inconsistencies, one has to deny access to the replicas until all replicas have the same state again - pessimistic techniques (Saito \& Shapiro, 2005). These procedures lead to a restriction of the availability or accessibility of documents, i.e., transferred to the cooperation context, to a 
reduction of cooperation possibilities. Moreover, the user is not involved in conflict resolution because conflicts are avoided a priori. Optimistic techniques assume that conflicts rarely occur in reality. If they do occur, they can be resolved after the fact. Consequently, concurrency control is low and only weak consistency is guaranteed. However, the availability of - possibly inconsistent - information objects to the user is high. Replication methods can be applied to both structured data and documents/files. Since documents play an essential role in asynchronous cooperation and the availability required for cooperation is the focus of this approach, the optimistic approaches of file synchronizers for conflict resolution in cooperation support systems are discussed below.

A distinction is made between a state-based and an operation-based file synchronizer. In statebased file synchronization, consistency between two replicas is achieved by sending all state data from one replica to the other. After all state data is received, operations are computed by taking a difference (delta) between the received state and the persistent state of the last successful synchronization. These operations are then applied by the consistency algorithm to both replicas at their respective locations to synchronize the replicas (Uppoor et al., 2010; Li et al., 2012). The operation-based file synchronizers use logs that record all operations that have occurred on each replica since the last consistency check. These operations are time-ordered and applied to the replicas to achieve a consistent state as a result (Ramsey \& Csirmaz, 2001; Najafzadeh, 2018). However, both approaches can lead to conflicts since operations can be performed, or replication states can be changed simultaneously.

Conflicts can either be resolved automatically (Ng \& Sun, 2016; Bjørner, 2007; Tao et al.; 2015, Bao et al., 2011), semiautomatic depending on the operation (Lindholm et al., 2005) or by the user (Balasubramaniam \& Pierce, 1998; Ramsey \& Csirmaz, 2001; Csirmaz, 2018). While there are approaches that attempt to take semantics into account (Tao et al. 2015), in principle, all file synchronizers operate more or less on a technical-syntactical level. Automatic conflict resolution may subsequently lead to results that do not meet consistency requirements from a cooperation point of view. When involved in conflict resolution, the user needs information about the context of the cooperation, i.e., the current goals, constraints, availabilities, intentions of the parties, restrictions, etc. However, this contextual information is not offered by file synchronizers.

Another approach to achieving document consistency is to assign access rights to files or directory systems (Dell, 2020; Microsoft, 2021b; Google, 2021b), which can be defined by the user. As with file synchronizers, however, there is a trade-off between availability and maintaining consistency. Restrictive access rights settings ensure consistency but hinder collaboration. The exceptional situation described in the scenario of the introduction chapter cannot be supported. Regardless of this, the question arises as to who sets the access rights and, if necessary, allows violations or exceptional situations.

Basically, a purely technical, syntactical level for ensuring the consistency of documents in the context of cooperation support systems does not seem to be sufficient but must be reconsidered:

... the role of the computer can thus be seen as that of providing sufficient feedback and affordances of shared objects to support ... the mediation of interactions by humans themselves (Greenberg \& Marwood, 1994, page 211).

In the 1990s, research in the area of awareness in cooperation support systems intensified. Awareness is defined here as "an understanding of the activities of others that provides a framework for one's own activities"(Dourish \& Bellotti, 1992, page 107). Subsequently, the term awareness was specified and differentiated into informal, social, workplace awareness, and awareness about group structure (Gutwin et al., 1996). Parallel research has been conducted in the area of document access rights in cooperative support systems that considered the aspect of awareness (Rodden et al., 1993; Greenberg \& Marwood 1994; Bäcker \& Busbach 1996; Busbach, 1996), which at its core is based on optimistic access control and conflict resolution by participants of the cooperation. However, a general approach to access rights has not yet been developed, as the combination of awareness and file synchronization seems to solve the problem. However, there is not yet an approach for comprehensive integration of these two concepts. The question of who is ultimately responsible for the content of a document, or the question of traceability of responsibility, also remains open. First approaches to this aspect can be found in 
(Busbach-Richard, 1999). However, the aspect of access coordination has moved out of the focus of research on cooperation support systems, leaving unresolved questions such as "who is allowed to execute what, when and why, or in which context on files/documents". It is only in the context of the idea of smart contracts (Kolvart et al. 2016; Jaccard, 2017) that this question and thus the aspect of responsibility has come back into focus. Although at first glance, aspects of semantics and collaboration context are mapped in this approach, the real implementations are mostly still on a technical-syntactical level. The meaning of terms such as owner, possessor and subsequently responsibility are not defined yet. The transfer of concepts from the legal domain to the consistency maintenance of documents in distributed systems or cooperation support systems is insufficient. For example, Google Drive and Adobe use the term ownership (Google 2021b; Adobe 2021), but further research reveals that the term is not defined. The following table summarizes the advantages and disadvantages of the optimistic and pessimistic approaches.

Table 1. Overview of approaches for access coordination in shared workspaces (Source: compilation by the author)

\begin{tabular}{|l|l|l|}
\hline type & optimistic & pessimistic \\
\hline pros & does not hinder the flow of cooperation & $\begin{array}{l}\text { consistency - at least at the syntactical level - is } \\
\text { ensured }\end{array}$ \\
\hline cons & $\begin{array}{l}\text { consistency can be compromised, } \\
\text { leading to inefficiencies and errors }\end{array}$ & $\begin{array}{l}\text { can hinder the flow of collaboration and even lead to } \\
\text { a temporary blockade }\end{array}$ \\
\hline prerequisites & $\begin{array}{l}\text { all participants involved in the } \\
\text { cooperation must be aware of potential } \\
\text { access conflicts and know about conflict } \\
\text { resolution schemes to enable conflict } \\
\text { resolution on a semantic level }\end{array}$ & $\begin{array}{l}\text { access rights must be set appropriately to minimize } \\
\text { interference with cooperation, and one person must } \\
\text { be responsible for adjusting access rights to resolve a } \\
\text { temporary blockade }\end{array}$ \\
\hline
\end{tabular}

\section{Research Methodology: Legislation - Ownership vs Possession}

In Western democracies, a distinction can be made between common law and civil law (UC Berkeley, 2017). Common law is generally not codified and works with precedents. In general, everything is permitted that is not expressly prohibited by law (World Bank Group, 2021). Civil law, whose origins can be found in Roman law (UC Berkeley, 2017), is, in contrast, a codified legal system (World Bank Group, 2021), whose description of legal relations is more on an abstract level (Rahmatian, A. 2010) and allows less freedom, for example, in the formulation of contracts (World Bank Group, 2021). Although the optimistic approaches have proven more advantageous here for the cooperation case, civil law - more specifically, the German Civil Code (BGB) - will be discussed in more detail below. The abstraction of civil law contains an unambiguous description of the terms of ownership and possession, which is not given in this form in the common law. Since these terms are only vaguely defined in the current implementation of shared workspaces, the consideration of codification from the field of civil law can provide valuable impulses for the cooperation context.

Both legal systems have in common that property law defines the objects of property as defined by law, regardless of whether they are tangible or intangible. Exclusive rights are conferred on these objects or "things." These rights, property rights, are socially recognized and legally protected and create (initially) exclusive powers over these objects - ownership. Thus, property law creates objects as normative concepts and assigns these objects to natural or legal persons by conferring rights over them (Rahmatian, 2010).

A closer look at the BGB shows that the owner of an object is the person to whom the object belongs. In Germany, the constitution guarantees and protects the right of ownership according to Article 14 of the Basic Law (GG). The BGB defines the content and protection in more detail in $\S \S 903 \mathrm{ff}$. However, the legislator must also consider the interests of the general public as well as the interests of the persons who come into contact with third party property rights. This balancing of interests is already laid down in $\S \S 903(1)$ BGB, when it states, 
$"$... unless the law or the rights of third parties conflict therewith, .... ".

Property is therefore not granted unconditionally but is subject to restrictions (Van der Walt \& Dhliwayo, 2017). In German law, this aspect is enshrined in $\S \S 14$ of the Basic Law, which states that there is a social obligation of property.

Property is a right but not yet a claim against a particular person. Only from the violation of the property right, i.e. the impairment of the thing of which one is the owner, do claims arise against the violator(s) of the property (Juracademy, 2021). Property violations may include interference with property, compensation for unauthorized use, damages, protection against unauthorized disposition, and protection against deprivation of possession.

Within the scope of this article, it is not possible to deal with all infringements of property rights as defined in German law. However, of particular interest is the last point, protection against deprivation of possession, which relates to the difference between possession and ownership. In contrast to ownership, possession is understood as the actual power of disposal over a thing. That is, one can be an owner without possessing, as in the case of borrowing, renting, or even stealing. Material control (possession) is to be distinguished from legal control (ownership). Ownership and possession may coincide. However, this need not necessarily be the case.

A small example: in the case of an apartment, on the one hand, there is the owner of the apartment, and on the other hand, there is the tenant, who has concluded a rental agreement and thus becomes the possessor of the apartment. The lease gives the possessor protection of possession and the right to defend this possession against others. One also speaks of direct possession since the power of disposal is exercised. The owner is referred to as the indirect possessor. He has the legal power of disposal. One can even gain possession of a thing through a criminal act, for example, a theft, even though one has violated the law, since the crime gives one the material power of disposal. This, of course, violates property rights, which have a higher value than this so-called tortious possession. Possession can be handed over by a contract or simply using the thing.

The BGB has some regulations that also protect possession (Juraforum, 2021a). For example, there is the right of force according to $\S \S 859 \mathrm{BGB}$. The holder of the right of force may use force to defend himself against the opponent of the possession - the person who wants to take the thing illegally - in order to protect the possession in case of interference with the possession with his own force, provided that the means of force is suitable, necessary, and proportionate.

In addition to possession, ownership as such can, of course, also be transferred. In BGB, the transfer of ownership of an object requires an (informal) agreement between the parties that ownership of a particular thing is to be transferred (contract in rem) and the transfer of the thing (handover) as an actual act. If the thing is already in possession of the acquirer, ownership may be transferred by the mere agreement between the parties that the new owner (acquirer), who previously held the thing with the intention of possessing it for the transferor, shall now exercise possession for himself: traditio brevi manu. Thus, the possessor for another person becomes the possessor for himself and thus the owner (Rahmatian, 2010).

As a rule, the informal agreement discussed above must follow the construct of a contract. A contract is a multilateral legal transaction that establishes a debt relationship between the parties. A contract only becomes effective if there are at least two corresponding declarations of intent, namely offer and acceptance, regarding the essential content of the contract. Acceptance presupposes the submission and receipt of the offer. However, the timeliness of the acceptance in accordance with $\S \S 147$ und $\S \S 148$ BGB must be ensured. Acceptance is subject to time constraints. However, a contract is not validly concluded despite the effective existence of an offer and acceptance if so-called objections that hinder the right stand in the way, such as legal incapacity or due to a breach of a statutory prohibition. In addition, a validly concluded contract can "lapse", i.e., the contract was void from the start if the declaration of intent made is contested by the declarant. The German Civil Code lists, for example, the following grounds for rescission (§§ $142 \mathrm{I}, 143,119 \mathrm{ff} . \mathrm{BGB})$ : error of content, error of declaration, error of quality, false transmission, fraudulent misrepresentation, or threat (Juraforum, 2021b). 


\section{Research results: Access Coordination in Shared Workspaces}

In the following, the notions of ownership, possession and - indirectly - contract are transferred to a cooperation context.

\section{Ownership}

Several basic assumptions need to be made in order to adapt the legal concept of ownership to shared workspaces, which reflects the rights and obligations of an owner:

- It is assumed that hat transferring the notion of ownership to a cooperation context can contribute to the emergence of commitment, since individuals can be held directly responsible for information used in cooperation.

- The person who contributes information - be it in the form of a document, a discussion contribution, an email, etc. - to a cooperation is referred to as the (initial) owner and originator. However, this can only apply in relation to the cooperation-specific shared workspace. Outside of the cooperation context, the term owner loses its meaning.

- By contributing information, an owner commits to ensuring the best possible availability and consistency under the current circumstances of the cooperation. This includes resolving or mitigating conflicts regarding the information object through negotiation. This is done in analogy to the legal concept of ownership that the interests of the general public must be considered.

Against the background of the last assumption, the owner must actively prevent interference with his information. Conflicts can also arise from passive influences on the property, such as when the contents of documents contradict each other or when the content of a contribution to a discussion is interpreted and construed contrary to the owner's original intention. However, resolving passive influences requires that at least one party - not necessarily the owner himself discovers and addresses this influence.

Ownership in a collaborative context arises from the provision of information. The person providing the information is the originator and the initial owner. Ownership can be passed on, not authorship. The importance of this separation can be illustrated, for example, by a discussion post. The discussion post itself reflects the author's opinion, while the owner coordinates the information object that contains the author's opinion. The second way in which ownership can be acquired within cooperation is through the transfer of ownership. The transfer of ownership requires an agreement between the new and the old owner, i.e., as with a legal contract, two corresponding declarations of intent are required, namely offer and acceptance. In the time window between the submission of the offer and the acceptance of the ownership, the information must remain "unchanged" or may only be changed within clear specifications to be defined in the offer. If the defined time frame for acceptance has expired, the transfer of ownership has failed. The voluntary nature of acceptance is essential. No party to cooperation can be forced to assume the obligations of an owner. This coincides with the concept of free will from contract law.

\section{Possession}

By analogy with the legal term, the possessor of an information object is the person who accesses and/or edits the object as part of a cooperation. The operations that a possessor can perform include reading and writing the content and moving the information object. If one transfers the legal concept of material possession to shared workspaces, further conclusions can be drawn:

- In contrast to the legal concept of possession in the German Civil Code, possession in the context of cooperation is of a more short-term nature in order to prevent a permanent blockade of the cooperation from the outset. The exercise of possession rights within the framework of cooperation is bound to a certain period of time. When the current operation ends, so does the possession. Possession is volatile.

- The possessor's guarantee to be able to execute an operation that has been started or granted is subordinate to the owner's rights and obligations, as the owner must ensure the best possible availability and consistency for all cooperation participants. 
- Another limit to the transfer of the notion of material control in the context of cooperation is the fact that in German law, there can be at most one legal possessor or group of possessors at any given time. In this context, a group of possessors is homogeneous from a legal point of view. In cooperation, on the other hand, several possessors can act simultaneously and independently of each other on an information object. Material possession of information objects within cooperation need be neither exclusive nor homogeneous.

Apart from the (possible) interaction with other possessors, the actions of a possessor are, in any case, always integrated into the general cooperation context. Other cooperation participants - even if they are not possessors at the moment - can be influenced in their actions by the possession of another cooperation participant. The actions of a possessor do not only influence the possessor himself but on the entire cooperation.

At first glance, conflict resolution in access coordination of information objects appears to be straightforward as the owner, as the holder of the legal power of disposal, determines the validity of an information object and can withdraw possession - thus maintaining availability and consistency for all participants in the collaboration. However, a closer look reveals a more complex or differentiated picture. Moreover, there are additional ownership/ownership and possession/possession conflicts to consider. The following table provides an overview.

Table 2. Overview of conflict types (Source: compilation by the author)

\begin{tabular}{|l|l|l|l|l|}
\hline $\begin{array}{l}\text { conflict } \\
\text { type }\end{array}$ & ownership/possesion & $\begin{array}{l}\text { ownership/ownershi } \\
\text { p }\end{array}$ & $\begin{array}{l}\text { possession/posse } \\
\text { ssion } \\
- \text { exactly one } \\
\text { possessor at a } \\
\text { time }\end{array}$ & $\begin{array}{l}\text { possession/possession - } \\
- \text { two possessors at one } \\
\text { time }\end{array}$ \\
\hline $\begin{array}{l}\text { resolution } \\
\text { scheme }\end{array}$ & $\begin{array}{l}\text { a) explicit approval by the } \\
\text { owner of changes made by the } \\
\text { possessor without the } \\
\text { appropriate consent of the } \\
\text { owner. Time restrictions may } \\
\text { apply } \\
\text { b) transfer of ownership of the } \\
\text { information object to the } \\
\text { possessor of the information } \\
\text { object. } \\
\text { c) Rejection of the changes by } \\
\text { the owner of the information } \\
\text { object } \\
\text { d) Rejection of changes by the } \\
\text { owner of the parent folder } \\
\text { (possibly cascading) - for more } \\
\text { details on this, see } \\
\text { ownership/ownership conflict } \\
\text { of the folder by the } \\
\text { owner of the } \\
\text { information object } \\
\text { b) transfer of } \\
\text { ownership of the } \\
\text { information object } \\
\text { to the owner of the } \\
\text { folder } \\
\text { c) removal of the } \\
\text { information object } \\
\text { from the folder }\end{array}$ & $\begin{array}{l}\text { a) Current } \\
\text { possessor } \\
\text { relinquishes } \\
\text { possession. }\end{array}$ & $\begin{array}{l}\text { Subsequently, } \\
\text { another } \\
\text { cooperation } \\
\text { participant may } \\
\text { gain possession } \\
\text { (b) owner } \\
\text { approves } \\
\text { changes after the } \\
\text { fact. Time } \\
\text { restrictions may } \\
\text { apply. }\end{array}$ & $\begin{array}{l}\text { competing: } \\
\text { a) decision about the } \\
\text { correct object state by } \\
\text { the owner, combining } \\
\text { changes of both } \\
\text { possessors if necessary } \\
\text { b) the last change is valid } \\
\text { (rule set transparently by } \\
\text { owner) } \\
\text { simultaneous: } \\
\text { a) allow for non- } \\
\text { modifiable access with } \\
\text { the indication of possible } \\
\text { inconsistencies } \\
\text { b) allow for non- } \\
\text { modifiable access and } \\
\text { provision of a } \\
\text { notification service for } \\
\text { any change to the } \\
\text { information object }\end{array}$ \\
\hline
\end{tabular}

\section{Ownership/possession conflict}

Within the ownership/possession conflict, there are different constellations. For example, the question of responsibility remains open if the possessor makes changes and then the object is further processed by third parties without the owner being able to check and approve these changes before they are passed on. In the description of the cooperation scenario in the introduction to the article, such a situation is described. In principle, this case can be solved in two ways. Either the ownership right on the information object is transferred to the possessor, and he will become the new owner. This approach corresponds to the "traditio brevi manu" of the German Civil Code. The possessor for another becomes the possessor for himself. Alternatively, the right of ownership remains with the owner. The latter bears the responsibility outwardly towards third parties, but he can claim from the possessor in the internal relationship. This corresponds to the legal approach of compensation in case of damage or compensation in case of unauthorized use if the owner has deprived the possessor of material control. Of course, the owner 
can also approve subsequent changes if the right of possession was originally exercised without appropriate authorization. Alternatively, the changes are rejected by the owner and the information object is restored to its original state. In this case, the other participants in the cooperation who have accessed the object in the meantime must be informed of the incident, as they may have worked on the basis of incorrect information. If necessary, their work must be undone.

In addition to direct ownership/possession conflicts that have been played out in the scenario, there are also indirect conflicts. These can occur when an owner of an information object grants a right of possession that conflicts with the ownership rights of the folder in which the information object has been uploaded. For example, the owner of the folder may have specified that the information objects stored in the folder may not be modified. The owner of the information object nevertheless allows modifying access. There is no conflict between the owner of the information object and its possessor but an indirect conflict between the owner of the information object and the owner of the folder. For resolution or avoidance, it must apply that an owner can grant to another person only those possession rights that he himself still has after restricting his ownership rights with respect to the folder's rules. The possible material control rights must preserve the ownership rights that exist on the folder. From the possessor's point of view, this example involves a concrete ownership/possession conflict regarding the information object, although the possessor did not trigger it. The owner of the folder can either accept the changes even though the ownership was incorrect. Alternatively, he can reject the changes. Since there are folder hierarchies, this procedure can be cascading.

\section{Ownership/ownership conflict}

Looking at the above scenario more closely from the perspectives of the owner of the folder and the owner of the information object, an abstract ownership/ownership conflict arises. The rights of one owner are restricted against his will by those of another owner. In this case, however, it is not the rights of the owner of the information object that are restricted or infringed, but those of the owner of the folder. By uploading the information object in the folder, its owner has freely restricted himself to the rules set by the owner of the folder. Consequently, these restrictions did not happen against the will of the owner of the information object since the procedures were known in advance. Conversely, the owner of the information object may be affected if the owner of the folder tightens or relaxes the rules for the folder. If these options are part of the rule set for the folder and are transparently viewable, no conflict occurs because the procedures were known at the time the information object was uploaded. The changes are consistent with the original agreement. However, a conflict arises if the owner of the folder changes the ruleset after upload of the information object in a way that was not known at the time of upload. One solution, in this case, might be for the owner of the information object to remove it from the folder. Another solution could be that the owner of the folder becomes the owner of the information object.

\section{Possession/possession conflict}

The scenario in the introduction of the article contains a case for a simple possession/possession conflict. The constellation in which Anna is the possessor, Clara has the right of ownership, and Bert wants to make changes leads to a corresponding conflict since Bert has not come into possession either through an intervention by Clara, who would first have to deprive Anna of possession and transfer it to Bert or through a release of possession by Anna. In this scenario, however, it is assumed that there is only one possessor at a time.

As described above, in a cooperation context can be more than one possessor for an object at the same time. As a result, two-possession/possession conflicts may occur, competing conflicts and simultaneous conflicts. Competing conflicts can occur when an owner grants multiple people the right to modify the information object. Possessors compete over the validity of the modifications they make to the information object. The owner of the information object decides on the correct state of the object. He can combine the changes made by the two possessors, if necessary, or decide in favor of a single change. Another solution is that the owner of the information object transparently sets a rule that the last change is valid. A simultaneous conflict can occur when a non-modifying possession right is granted concurrently with a modifying possession right. Now the problem arises as to which state of the information object is observed by the person who has 
been granted a non-modifying possession right. One solution is that the participant in the cooperation who is granted non-modifying access is transparently informed about the possibility that the information object may be modified during his possession. In this case, he is aware of possible inconsistencies in the state of the object and can adjust his work and decisions to this uncertainty. A second solution is to combine the allowance for non-modifying access with a notification service. Any possessor granted non-modifying access will be notified of changes of the information object so that they can tailor their work and decisions to the current state of the object. Although this seems to be a solid solution, problems related to network outages and notification overflow can occur.

It is not self-evident that both possessors can exercise their rights of possession without restriction. It depends on the owner's grant of possession whether he avoids any possible conflict or allows them to arise. In the latter case, an owner must disclose the conflict resolution rules, i.e., all persons seeking possession are informed of the rules and agree to them by accepting possession. The owner has an obligation to indicate the possibility of conflicts and their conditions. Possessors are aware that the owner is the final arbitrating and deciding authority regarding the validity of an information object.

\section{Conclusions}

If we transfer the legal concepts of the owner, possessor and - indirectly - contract to a cooperation context, innovative coordination structures emerge when accessing information objects. Availability is increased while maintaining a certain consistency since the responsibilities for an information object are clearly defined in a cooperation context. In this respect, the purely technical, syntactically oriented procedures from the field of distributed systems, file synchronizers and directory services are extended to include a semantic level for maintaining consistency. The individual participants in the cooperation are personally involved in the coordination of information objects through their consent to the cooperation. Consent creates commitment and acknowledges potential constraints. Awareness is enriched with semantics that relates to access coordination. Direct involvement of individuals leads to self-regulation, resulting in indirect enforcement of coordination structures. Each action is directly coupled to an individual. This coupling is visible to all cooperation participants. However, it can be assumed that selfregulation through personal responsibility is correlated with group size. If a too large number of cooperation partners leads to the depersonalization of responsibility, this may increase the need for institutionalized coordination structures. Testing this assumption and investigating whether and which awareness concepts for access coordination are built up among participants in detail would be an area for further research.

However, the transfer of legal concepts is far from complete. The question arises as to whether, in an even more detailed analysis, there are further areas of access coordination to shared workspaces that require an expansion of legal concepts, such as the case of concurrent and simultaneous possession, which do not exist in this form in the legal field. Furthermore, the question arises to what extent the approaches of Smart Contracts (Kolvart et al., 2016) map the legal concepts of contract from the German Civil Code and whether - after appropriate adaptations - they can possibly be integrated into an implementation for access coordination of information objects in shared workspaces. However, the adaptation of the legal concept of the contract was only indirectly addressed in the article and requires further investigation.

Of course, access coordination of information objects within cooperation must be adapted to the changing conditions in the course of the cooperation. The adaptation is made by the participants of the cooperation. On the one hand, it can be done explicitly by changing the coordination procedures or implicitly by reinterpreting or abandoning the use of existing procedures. The second point correlates, on the one hand, again with the awareness concept. On the other hand, this point crystallizes another aspect that has always been present subliminally in the transfer of legal concepts to access coordination: semantics. Legal terms such as ownership, possession, and contract are interpreted in a particular context. Depending on the context, the interpretation may change. The same is true for the transfer of these terms to cooperation in a shared workspace. The conclusion from this is that, in contrast to the classical concept of algorithms in computer science, there can be ambiguity. Algorithms always deliver the same result with the same input. There is 
no interpretation. Algorithms cannot capture semantics. This is mathematically proven since semantics belongs to the so-called np-hard problems, which are not computable (Knuth, 1974). Semantics can only be emulated by artificial intelligence methods. However, these methods do not correspond to the classical notion of an algorithm because, depending on the learning state of the methods, the same input can lead to different results at different times as context changes are taken into account. Similar to a legal system, there is no uniqueness of outcomes. Transferred to the context of cooperation, this means that there is no optimal solution for the access coordination of information objects, but only an approximation. Either purely technical, syntactically oriented procedures from the field of distributed systems, file synchronizers and directory services are used, which may hinder the flow of collaboration and even lead to a temporary blockade. However, consistency at the syntactic level is guaranteed. Alternatively, a common context space can be created to avoid misunderstandings using legal terms such as ownership and possession. Nevertheless, misunderstandings cannot be excluded in principle since - as explained above - an algorithmic solution for the semantics of the concepts of owner and possessor does not exist. To improve the use of the concepts of ownership and possession in a cooperation context and to reduce possible misunderstandings, further research can investigate whether concepts from the field of design patterns (e.g., Alexander et al., 19770 can be applied to develop consistency control patterns that can support access coordination depending on the concrete problem context.

\section{References}

Adobe (2021). File systems access permissions [online], https://devdocs.magento.com/guides/v2.4/configguide/prod/prod_file-sys-perms.html [10.08.2021].

Agostini, A., De Michelis, G., Grasso, M.A., Prinz, W., \& Syri, A. (1996). Context, work process and workspaces. Computer Supported Cooperative Work: Journal of Collaborative Computing, 5(2-3), 223250.

Alexander C, Ishikawa S, Silverstein M (1977) A pattern language: towns, buildings, construction. Oxford University Press.

Bäcker, A. \& Busbach, U. (1996). DocMan: A Document Management System for Cooperation Support. In: Proceedings of 29th Hawai'i International Conference on Systems Sciences. IEEE Computer Society Press, pp. 82-91.

Balasubramaniam. S. \& Pierce. BC (1998). What is a File Synchronizer?. In: Proceedings of the 4th Annual ACM/IEEE International Conference on Mobile Computing and Networking. ACM, Press, pp. 98-108.

Bao, X., Xiao, N., Shi, W., Liu, F., Mao, H. \& Zhang. H.(2011). SyncViews: Toward Consistent User Views in Cloud-Based File Synchronization Services, Proceedings of the 6th Annual Chinagrid Conference, pp. 89-96.

Bentley, R., Appelt, W., Busbach, U., Hinrichs, E., Kerr, D., Sikkel, K., Trevor, J. \& Woetzel, G. (1997). Basic support for cooperative work on the World Wide Web. International Journal of Human-Computer Studies, 46(6), 827-846.

UC Berkeley (2017): THE COMMON LAW AND CIVIL LAW TRADITIONS [online], https://www.law.berkeley.edu/wp-content/uploads/2017/11/CommonLawCivilLawTraditions.pdf [24.08.2021].

Bjørner, N. (2007). Models and Software Model Checking of a Distributed File Replication System. In: Jones C.B., Liu Z., Woodcock J. (eds) Formal Methods and Hybrid Real-Time Systems. Vol. 4700. Lecture Notes in Computer Science. Springer, 2007, pp. 1-23.

Busbach, U. (1996). Activity Co-ordination in Decentralized Working Environments. In: Dix A, Beale (eds): Remote Cooperation - CSCW issues for Mobile and Tele-workers. Springer, pp. 95-112.

Busbach-Richard, U. (1999). In Analogy to Juridical Systems: An Access Co-ordination Framework for Shared Workspaces. In: Proceedings. of the 7th Interdisciplinary Information Management Talks. Trauner, pp. 165-172.

Csirmaz, E. (2018). Algebraic File Synchronization. Adequacy and Completeness [online], https://arxiv.org/pdf/1601.01736.pdf [11.08.2021].

Dell (2020). Understanding File and Folder Permissions in Windows [online], https://www.dell.com/support/ kbdoc/ de-de/000137238/understanding-file-and-folder-permissions-in- 
windows?lang=en [10.08.2021].

Dourish, P. \& Bellotti, V. (1992). Awareness and Coordination in Shared Workspaces. In: Proceedings of the Conference on Computer-Supported Cooperative Work. ACM Press. pp. 107-114.

Google (2021a). Share files from Google Drive [online], https://support.google.com/drive/ answer/2494822?hl=en\&ref_topic=7000947 [20.07.2021].

Google (2021b). Control access to files and folders in shared drives [online], https://support.google.com /a/answer/7662202?hl=en [24.07.2021].

Greenberg, S. \& Marwood D. (1994) Real Time Groupware as a Distributed System: Concurrency Control and its Effect on the Interface. In Proceedings of the Conference on Computer Supported Cooperative Work. ACM Press, pp. 207-219.

Gutwin, C.; Greenberg, S. \& Roseman, M. (1996): Workspace Awareness in Real-Time Distributed Groupware: Framework, Widgets, and Evaluation. In: Proceedings of the Conference. on Human-Computer Interaction: People and Computers (HCI). Springer, pp. 281-298.

Jaccard, G. (2017). Smart Contracts and the Role of Law [online], https://jusletterit.weblaw.ch/issues/2017/23-November-2017/smart-contracts-and-_42155d7e26.html [22.02.2021].

Juracademy (2021). DER EIGENTUMS- UND BESITZSCHUTZ IM ÜBERBLICK [online], https://www.juracademy.de/sachenrecht1/eigentums-besitzschutz-ueberblick.html, [24.08.2021] in German.

Juraforum (2021a). Besitz - Definition und Erläuterung, Unterschied Besitz und Eigentum [online], https://www.juraforum.de/lexikon/besitz, [19.08.2021] in German.

Juraforum (2021b). Vertrag - Definition, Gültigkeit undZustandekommen nach $\S \S 145 \mathrm{ff}$. BGB [online], https://www.juraforum.de/lexikon/besitz, [21.08.2021], in German.

Knuth, D. (1974). Postscript about NP-hard problems. ACM SIGACT News. 6(2), 1516.

Kreifelts Th, Hinrichs E, Klein KH, Seuffert P, Woetzel G (1991). Experiences with the DOMINO office procedure system. In: de Michelis G., Simone C., Schmidt K. (eds) Proceedings of the Second European Conference on Computer-Supported Cooperative Work 25-27 September 1991, Amsterdam, The Netherlands. Springer, pp. 117-130.

Kreifelts T., Hinrichs E., Woetzel G. (1993). Sharing To-Do Lists with a Distributed Task Manager. In: de Michelis G., Simone C., Schmidt K. (eds) Proceedings of the Third European Conference on ComputerSupported Cooperative Work 13-17 September 1993, Milan, Italy. Springer, pp. 31-46.

Kolvart, M., Poola, M., Rull, A. (2016) Smart Contract. In: Kerikmäe, T., Rull, A. (eds) The Future of Law and eTechnologies. Cham: Springer, pp. 133-147.

Kochovski, A. (2021). How to Transfer Ownership of Google Drive Folder in 2021: Taking control [online], https://www.cloudwards.net/transfer-ownership-google-drive/ [21.07.2021].

Li, Q., Zhu, L., Shang, W., Zeng, S. (2012): CloudSync: multi-nodes directory synchronization. In: Proceedings of the International Conference on Industrial Control and Electronics Engineering. IEEE Computer Society Press, pp. 1470-1473.

Lindholm, T., Kangasharju. J. \& and Tarkoma, S. (2005). A hybrid approach to optimistic file system directory tree synchronization". In: Proceedings of the 4th ACM international workshop on Data engineering for wireless and mobile access, ACM Press, pp. 49-56.

Microsoft (2021a). OneDrive guide for enterprises [online], https://docs.microsoft.com/enus/onedrive/plan-onedrive-enterprise [21.07.2021].

Microsoft (2021b). FileSystemRights Enum [online], https://docs.microsoft.com/en-us/dotnet/api/system. security.accesscontrol.filesystemrights?view=net-5.0 [21.07.2021].

Najafzadeh, M., Shapiro, M. \& Eugster, P.(2018). Co-Design and Verification of an Available File System. In: Proceedings of the 19th Conference on Verification, Model Checking, and Abstract Interpretation. Cham: Springer, pp. 358-381.

Ng. A. \& Sun, C. (2016). Operational Transformation for Real-time Synchronization of Shared Workspace. In Cloud Storage”. In: Proceedings of the 19th International Conference on Supporting Group Work. ACM Press, pp. 61-70.

Rahmatian, A. (2010). A Comparison of German Moveable Property Law and English Personal Property Law [online], https://germanlawarchive.iuscomp.org/?p=340 [21.07.2021]. 
Ramsey, N. \& Csirmaz, E., (2001). An algebraic approach to file synchronization. ACM SIGSOFT Software Engineering Notes, 26 (5), pp 175-185.

Rodden, T., Mariani, J., Eiderbäck, B. \& Hägglund, P. (1993). Requirements for the COMIC Shared Object Service, in Requirements and Metaphors of Shared Interaction, COMIC Deliverable 4.1, pp 203-242.

Saito Y. \& Shapiro M. (2005). Optimistic replication. ACM Computing Surveys 37 (1), 4 -81.

Tanenbaum, A.S. \& Steen, M.van (2002). Distributed systems: principles and paradigms. Upper Saddle River, NJ: Pearson Prentice Hall.

Tao, V., Shapiro, M. \& Rancurel, V. (2015). Merging Semantics for Conflict Updates in Geo-distributed File Systems". In: Proceedings of the 8th ACM International Systems and Storage Conference. SYSTOR 15 ACM, Press Article No.: 1, pp 1-12.

UC Berkeley (2017): THE COMMON LAW AND CIVIL LAW TRADITIONS [online], https://www.law.berkeley.edu/wp-content/uploads/2017/11/CommonLawCivilLawTraditions.pdf [24.08.2021].

Uppoor, S., Flouris, M. D. \& Bilas, A. (2010). Cloud-based synchronization of distributed file system hierarchies. In: IEEE International Conference On Cluster Computing Workshops and Posters (CLUSTER WORKSHOPS), pp. 1-4.

Van der Walt, A.J. \& Dhliwayo, P. (2017) The Notion of Absolute and Exclusive Ownership: A Doctrinal Analysis. South African Law Journal, 134(1) 2017, pp. 34 -52.

World Bank Group (2021): Key Features of Common Law or Civil Law Systems [online], https://ppp.worldbank.org/public-private-partnership/legislation-regulation/framework-assessment/legalsystems/common-vs-civil-law [22.08.2021]. 